thigh. These papules may go on to vestculation, and discharge a clear fluid, constitutiog what used to be called lichen agrius. These conditions are now almost universally regarded as papular varieties of eczema. The disease of which I show you an example is one which is recognised and described und $r \mathrm{r}$ the above title by Mr. Erasmus Wilson and Drs. Hilton Fagge and Liveing. The last author gives a very accurate and graphic clinical account of the condition, but I shall venture to differ from him as to its pathology and the consequent treatment. Its position is a strong diagnostic feature; it is almost entirely limited to a triangnlar space upon the hack, of which the base is at the shoulders and interscapular region, and the apex may reach to the lumbar region. In front the eruption occupies more or less of the chest, spreading from the median line. In slight cases the middle line in front and behind, and its immediate neigh. bourbood, are the parts seized upon. The eruption consists of rings and small groups of papules, whirh tend to spread at the circumference into rings, the papules forming a brightred, well-defined margin, while the skin in the centre is either yellow or, more commonly, of a reddish-fawn colour. The rings may be perfect, and of considerable size, or they may meet others, and are then broken into gyrate lines, interspersed with isolated papules or small growths of two or three together; besides these rings, yellowish patches without papules at the margins may be seen. In these doubtless the papules have subsided, leaving only the stains behind. When the fawn-coloured discolorations are well developed, most people would be struck by its resemblance to tinea versicolor, but when the rings are small all resemblance to this disease except the situation is lost; many competent observers also have searched in vain for the elements of a

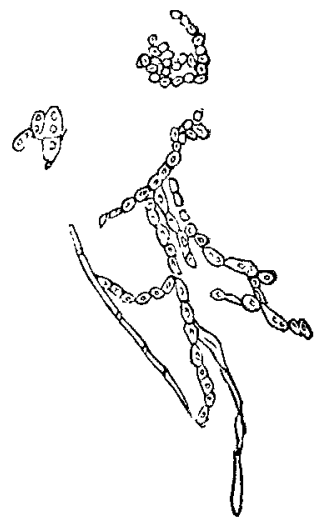

Fungus elements from a case of so-called Lichen circinatus. Magnified 550 diameters.

fungus. Yet I am convinced that it is a fungous disease, and my object to-day is to adduce both clinical and microscopic evidence that will convince you also.

Under the microscope you will see hoth spores and my. celium, which are upon the epithelial scales and also isolated; in size and appearance they correspond with the fungus of tinea versicolor. How is it that this fungue has escaped observation, as its nature is obvious enough? First, because the fungus is by no means so abundant as in the ordinary forms of tinea versicolor, and requires careful search, after teasing out of the epithelium and soaking in chloroform and ether to remove fatty particles, which I prefer to solution of potash, and, secondly, that the papular border furnishes the fungus, and not the discoloured part where débris, but not often perfect spores, can be found. But is the treatment founded on this pathology sucess-ful? I answer emphatically Yes. The disease, if left to itself, will last for months or even years, and yet local treatment alone with veuetahle parasiticides will remove the affection in two or three weeks, watchfulness is, however, necessary for some time, for, like the common form of this disease, it is liable to recur, doubtless because some of the spores have escaped destruction. The parasiticides I have used are sulphurous acid or hyposulphite of soda, one drachm to the ounce, brushed into the part; thymol, half a drachm to one ounce of vaseline, glvcerine of borax, and the acid nitrate of mercury ointment, diluted. Arsenic, which is recommended by some for in ternal administration, is never necessary. The late Dr. Tilbury Fox, in his classical work, alludes to papular and other aherrant forms of tinea versicolor, but does not describe this condition in detail, though he was evidently aware of it, but he alludes to even eczema heing excited by this fungus. In my opinion, therefore, we must expunge lichen circinatus as a separate affection from our list of skin diseases.
CASE OF

\section{SUPPURATION OF THE KNEE-JOINT, ASSOCIATED WITH PHTHISIS.}

AMPUTATION; RECOVERY, WITH DISAPPEARANCE OF CHEST SYMPTOMIS. ${ }^{3}$

BY THOMAS BRYANT, F.R.C.S. ENG, SURGEON TO GUY'S HOSPITAL.

Cirarles W-, aged twenty-three, a footman, was admitted on May 12th, 1881, into Job ward under Mr. Bryant's care. In February, 1878, he jumped from a loft about ten feet, and at the time felt no ill effects. About ten days afterwards he became feverish and very weak; he perspired a good deal, and had a bad cough. For three months he kept his bed. In August he went into the Can. terbury Hospital, where he was told he had rheumatism in his knee. His legs were dressed with spirit lotion, and $n$ a fortnight he was discharged. For three months he was in good health; the swelling had entirely disappeared from his knee, which he was able to bend. His knee, however, soon began to swell again, and became hot and painful. In July, 1879, he was admitted into Guy's, when his knee was swollen and felt pulpy to the hand. It measured $14^{\prime \prime} 25^{\prime \prime}$ against right $12.75^{\prime \prime}$. 'There was no fluctuation, but pain on pressure over the femoral condyles. There was then dulness at the base of the left lung. The knee was blistered and a posterior splint was applied. He was discharged Aug. 27th, wearing a Bavarian splint to ensure immobility of the joint, and with an elastic bandage beneath it for purposes of pressure. He wore his splint for two months, when his knee being much better he discontinued it. He was then able to bear his weight on his leg and bend the knee, and so resumed work,

Six weeks ago he jarred his knee when coming downstairs. The accident caused him much pain, and the joint in about two hours after swelled a good deal. He could, however, use the limb. The joint has since steadily grown worse. He has had hæmoptysis for the last three years, and a bad cough in winter. He perspires much at night.

On admission, May 12th, 1881, the knee was much swollen and displaced hackwards, the tissues around being very oedematous. The joint was clearly disorganised. The man lonked very ill and thin, and had a bad cough. There was dulness over both apices in front, and "couged" inspiration at both apices, but it was most marked on the lett side. There was prolonged expiration and bronchial hreathing at the left apex. Good resonance and vesicular murmur at the bases. He had had a good deal of hremoptysis, and his expectorations were muco-purulent.

June 7 th. - Under chloroform his leg was ampntated; an Esmarch bandage having been applied as a tourniquet after elevating the limb, antero posterior flaps were made. The anterior one was made by a semilunar incision reaching to about two inches below the condyles. The posterior flap was made by transfixion. The bone was sawn through above the condyles. All the vessels were twisted, except one large vein, which was ligatured with carbolised gut. Great care was taken to stop all oozing, by the use of sponges wrung out with hot iodine water, that quick union might en×ue. The flaps were brought touether by silk sutures one inch apart, strapping being applied in the intervals. The stump was washed with indine water, and adrainage-tube put in. The wound was dressed with terebene and oil, and the stump put upon a posterior splint. The knee, on examination, was in an advanced state of pulpy disease. The joint was ful of caseating pulpy material. The cartilage was removed from the external condyles, and the bone was covered witle granulations. The opposing surface of the tibia was in a less advanced condition. The underlying bıne washealtby. In places sinuses had begun to form. On the $13 \mathrm{th}$, the sixth day after the operation, the stump was dressed for the first time, when union of nearly the whole length of the wound was found to have taken place. On the 14th the patient was doing well. There was very little di-charge from the stump. Temperature $996^{\circ}$; pulse 100 . On the $17^{\circ}$ h secretion had diminished in quantity. On the 21 st, the fourteenth day afrer the operation, the drainage-tube was removed. Tem. perature $1012^{\circ}$, probably due to constipation. On the $23 \mathrm{rd}$ there was only a granulating surface of ahout a quarter of an

\footnotetext{
1 Read before the Medical Society of London, Oct. 24th, 1881.
} 
inch at the inner extremity of the wound. Uaron had taken place in the rest of its extent. Temperature $99^{\circ}$.- Chest examined: Right apex much improved since his arimission. Good resouance over the right apex, and farr over the lift, the only fult being a slight prolongation of the respiratory murmur. Left side iaspiration stıll cosged. Respiration still somewhat bronchial. At bases good vesicular murnur.

Oa July 14th the patient was dizeharred convalescent, and lookug comparatively woll. $\mathrm{He}$ had then no nightsweats, and did not spit blond. The stump had healed well, except at the inner extremity of the line of union of the flaps, where there was a very small granulating surface.

Remxrks.-I hive thought this case wirthy of being brought before the notice of this Society on account of the important practical point it illastrute;-namely, the value of removing losal suppurative disease, and more purticularly bone or joiat disease, when associated with lung mischief; and if it cannot be said in the case before na, from the want of lapse of time to enable us to form a positive judgment, that the or ranic disease which existed in the lung at the time of the amputation had disappeared, there can be no doubt that it had become quescent, and had apparently advanced towards cure; for when the man left the hospital all the local lung symptom: had ameliorated. and his general condition had greatly improved. It is to be noticed also that the wound after the amputation had almost entirely healed by quick or primary union. If I might venture to speak from my own personal observation, I atm convinced that the presence of local suppurative joint and bone disease, if it does not primarily originate lung trouble, does much to aggravate it and hasten its progress; while the case I have brought before you, in ardition to the experience gained by others which have passed under my care, clearly prove that by the removal of the local suppurative disease the lung mischief, which miy have been previously progressive, is retarded, if not cured; the lung disease by its presence affording an argument in favour of operative action rather than of delay. Uuder these circumstances, it clearly becomes the duty of the surgeon to employ his art actively rather than expectantly, and to take away by no partial but by some decided operative measure any local suppurative disease which by its progress has been proved to be incurable by natural processes, or from its nature is likely to require mn'h time for its repair. The case I have just read adds another to the list, which has been steadily lenuthening, in which this practice has proved successful, and it will, I trust, encourage surgeons to carry out the line of practice it illustrates. In lardaceous visceral disease the same line of practice should also be employed.

\section{THE INCUBATION PERIOD OF SCARLATINA, VARICELLA, PAROTITIS, AND RÖTHELN.}

BY CLEMENT DUKES, M.D., M.R.C.P., PHYSTCIAN TO RUGBY SCHOOL AND RUGBY HOSPITAL.

THE incubation period of all infectious ailments is so important a matter thit all who can contribute any facts concerning it are, I think, bound to do so. The incubation period cannot always be accurately calculated within twenty-four hours, for the case may not be seen at the very beginning, or it may be seen on the evening of one day and the next case in the morning, and so make a difference of a day in the calculation. I should state, in limine, that in all my cases the infectious individual, as soon as discovered, is at once removed from the house, so that there is no possibility of his proving a source of infection af ter the first few hours ; this fact is must important ia calculatiog the days. There is a possible source of fallacy in one's calcalations, which it is also most important to bear in mindnamely, slight undiscovered cases going about the whole time and infecting others freely ; for instance, in 1874, from May 12 th to July 3rd, I had ten cases of suarlatina, which went down without any order, and I could not trace their incubation period at all. Weeks after I found the reason was Mr. J. H. had scarlatina so slightly that he was about with it, and in school, the whole time, infecting at large ; this was only discovered by his hands being found peeling when he got home.
Tile Ifaubation of Scarlatina.

\begin{tabular}{|c|c|c|c|c|c|c|c|c|}
\hline $\begin{array}{l}0.0 \\
0.3 \\
\dot{z}\end{array}$ & $\begin{array}{c}\text { Initials } \\
\text { of } \\
\text { Patient. }\end{array}$ & Sex. & Age. & & ate. & $\begin{array}{l}\text { Resi- } \\
\text { dence. }\end{array}$ & $\begin{array}{l}\text { Possible } \\
\text { Surce of } \\
\text { rafeition. }\end{array}$ & $\begin{array}{l}\text { No. of } \\
\text { Days In- } \\
\text { cubating. }\end{array}$ \\
\hline 1 & P. & Male. & - & March & 21,1877 & $M r . W_{n}$ & & - \\
\hline 2 & C. & " & - & " & $27 "$ & " & No. 1 & 6 \\
\hline 3 & F. & ", & - & $\ddot{M}$ & $29 \quad "$ & $"$ & $N_{1} 1$ or 2 & 3 \\
\hline & $\mathbf{T}$. & ", & $\overline{12}$ & May & 7,1839 & Mr.'Wt. & & \\
\hline 6 & C. & ", & 10 & ", & 11, & $"$ & No. 5 & 4 \\
\hline & W. & ", & 10 & & & ", & No. 6 & 5 \\
\hline & T. & ", & 10 & & $16 \quad "$ & ", & No. 6 & 5 \\
\hline & R. & ", & 11 & " & 18 " & ", & No. 7 & 2 \\
\hline 10 & T. & ", & 9 & & $19, "$ & ," & No. 7 & 3 \\
\hline 11 & L. & , & 3 & & $20 "$ & ," & No. 9 & 2 \\
\hline & & & & & & & No. 9 & 2 \\
\hline & P. B. & ", & 11 & Jun $\theta$ & ${ }_{10}^{2} "$ & $"$ & (?) & $(?)$ \\
\hline 14 & w. & $"$ & 11 & Fëb. & $21,1 \ddot{3} 31$ & Mr.'E. & No. 13 & $7(?)$ \\
\hline $\begin{array}{l}16 \\
16\end{array}$ & C. & $"$ & 16 & & $2 . \overline{3}, "$ & , s. & No. 15 & 4 \\
\hline 17 & B. I. & ," & & 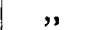 & 25, & ", & No. 15 & 4 \\
\hline 18 & H. & ", & & & & 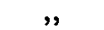 & No. 15 & 1 \\
\hline 19 & $\begin{array}{l}\text { H. } \\
\text { w. }\end{array}$ & " & is & roph & & " & No. 17 or 18 & 1 \\
\hline & & & & & & & 180.18 or 18 & \\
\hline
\end{tabular}

\section{Remarks.}

Case 2 said, "Sir, I'll tell you who will get ill next, Case 4, for I was with him on March 26 th from 3 to 4.30 P.M. and Case 3 will have it too, for I sat on the sofa here beside him for about twenty minutes on March 26 th."

Cise 5 (the school assembled on May 2nd, 1879) was probably caught en route, as there was none at home or at sehool (fifrh day).

Case 6 (immediately before Case 5 was removed) had some hot word;, and "head in chancery," I believe, with Case 5, because the former bad hit Case ऽ's little brother. Otherwise they never had anv communication with each other, either in bedroom, school-room, or dining-room.

Case 7 sat near or next to Case 6 .

Case 8 sat near or next to Case 6 . Brother to Case 5.

Case 9 was in the same set, and at the same table at meals, as the above four. Very great friends with Case 7.

Case 10 sits at school next to Case 7, and at meals opposite.

Case 11 sits next to Case 9 at dinner, and sleeps in next bed.

Case 12 sits next to Case 9 at meals; they occupy the same bedroom and are in the same class.

Case 13, on Miy 18th, sat next to Case 10 at tea, and was examining his face with Case 10 in the concave surface of a silver spooa. But as we had Case 12 in a bedroom next to Case 13's room, and as Case 13 had to go there every night, and from there every morning, and as the nurse who was nursing Case 12 had to pass several times a day over the same stairs and landing by which Case 13 had also to pass to get to his room, I think the latter source much more probahle than the former, which would be on the fourteenth day.

Case 14 rolled over Case 13 at 7 A.M on June 2nd, as soon as he heard that Case 13 had a sore-throat on purpose to catch it, as he thought it would be such fun. He showed rash on June 10th, so that the throat was bad the day before, and real incubation the seventh insted of the eighth day.

Case 16 worked with Case 15 the night before the latter was removed.

Case 15 was in Case 18's study on Feb. 21st, 1881.

Case 19 was intimate with Case 18 , and in the same bed. room as Case 17.

Case 20 sleeps next to Case 18, and shares the same study with Case 17.

Sqarlatina and Varicella at the same trme.

\begin{tabular}{c|c|c|c|c|c|c}
\hline $\begin{array}{c}\text { No. of } \\
\text { Case. }\end{array}$ & Initial. & Sex. & Age. & Resilence. & Scarlatina. & Varicella. \\
\hline 1 & W. W. & Male. & - & R. & March 19, 1880 & March 29, 1880 \\
2 & N. W & Fem. & - & R. & ", " & " " "
\end{tabular}

Remarks.

Cases 1 and 2 were placed in the fever cottage on March 19th, 1850, with scarlatina.

On March 2 th, 1880, I was asked to see A. and K. W. at home, and foun $t$ them suffering from varicella. On visiting Cases 1 and 2 at the fever cottage $I$ found both of them just showing varicella spots too.

All four were doubtless infected at the same time by a common infection. 